\title{
Albert Camus-René Char, Correspondance, 1946-1959
}

\section{Emanuele Kanceff}

\section{(2) OpenEdition}

\section{Journals}

\section{Edizione digitale}

URL: http://journals.openedition.org/studifrancesi/9669

DOI: 10.4000/studifrancesi.9669

ISSN: 2427-5856

\section{Editore}

Rosenberg \& Sellier

\section{Edizione cartacea}

Data di pubblicazione: 1 décembre 2007

Paginazione: 696

ISSN: 0039-2944

\section{Notizia bibliografica digitale}

Emanuele Kanceff, «Albert Camus-René Char, Correspondance, 1946-1959», Studi Francesi [Online], 153 (LI | III) | 2007, online dal 30 novembre 2015, consultato il 12 janvier 2021. URL: http:// journals.openedition.org/studifrancesi/9669; DOI: https://doi.org/10.4000/studifrancesi.9669

Questo documento è stato generato automaticamente il 12 janvier 2021.

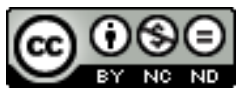

Studi Francesi è distribuita con Licenza Creative Commons Attribuzione - Non commerciale - Non opere derivate 4.0 Internazionale. 


\title{
Albert Camus-René Char, Correspondance, 1946-1959
}

\author{
Emanuele Kanceff
}

\section{NOTIZIA}

ALBERT CAMUS-RENÉ CHAR, Correspondance, 1946-1959. Édition établie, présentée et annotée par Franck PLANEILLE, Paris, Gallimard, 2007, pp. 263.

1 Si tratta della pubblicazione di 184 lettere inedite scambiate tra i due scrittori, dalla fine della Seconda Guerra mondiale alla morte di Camus, lettere che sono in maggioranza di Char, così come egli appare il protagonista in questo confronto, tanto che ci si chiede se sia un criterio di ordine alfabetico ad aver dettato il frontespizio. Se Émile Blanche avesse o no ragione di affermare «J'estime que l'art épistolaire est le genre littéraire le plus important», ciò non toglie che anche qui, come inevitabilmente avviene nelle corrispondenze tra scrittori, il dialogo che ne risulta, pur interessantissimo, è frammentario. Ancora di più in questo caso, tra due poeti che avevano molteplici occasioni di incontrarsi personalmente. Questo non toglie nulla all'interesse della pubblicazione, che anzi costituisce un bel capitolo nella vita e nei rapporti di due intellettuali che avevano molte ragioni per comprendersi e apprezzarsi a vicenda, ragioni che il curatore Franck Planeille bene illustra nella Prefazione. Egli, poi, ha compiuto un lodevole sforzo di datazione di questi documenti spesso non datati, relegando al fondo dell'edizione le lettere databili con incertezza o non databili. La pubblicazione è arricchita da una folta e illuminante annotazione, la quale, purtroppo, come è consuetudine, non si preoccupa di segnalare anche al lettore le questioni testuali, correzioni, cancellature, aggiunte, che pur emergono dalla trascrizione di questi inediti.

2 Indipendentemente da questi problemi puntuali, rimane la grande ricchezza e il grande interesse del dialogo di due protagonisti della cultura francese del Novecento che, in concordia e in amicizia, guardano l'uno all'opera dell'altro, per arricchirsene, 
ispirarsene e per condurre un cammino comune, per sostenersi contro la follia e l'errore del loro tempo, per confrontare i propri dubbi e risolvere le loro incertezze.

3 Un interessante apparato di «Annexes» e di documenti inediti completa il volume, ivi compreso un indice dei nomi, strumento utilissimo quanto raro in questi tempi di fretta. 